\title{
A esfera pública cultural e as modalidades de tornar comum
}

The cultural public sphere and the modalities

of making it common

Maria João Centeno - Escola Superior de Comunicação Social - IPL ICNOVA - Instituto de Comunicação da NOVA

mcenteno@escs.ipl.pt

https://doi.org/10.26619/978-989-9002-14-2.7

\begin{tabular}{|c|c|c|}
\hline $\begin{array}{c}\text { Recebido / Received } \\
11.06 .2020\end{array}$ & Aceite / Accepted & Publicado / Published \\
& 18.06 .2020 & 15.01 .2021 \\
\hline
\end{tabular}

Como citar este capítulo / How to quote this chapter:

Centeno, M. J. (2021). "A esfera pública cultural e as modalidades de tornar comum". In Lourenço, J. \& Lopes, P. (eds.), Comunicação, Cultura e Jornalismo Cultural Lisboa: NIP-C@M \& UAL, (pp. 138-162), disponível em https:// repositorio.ual.pt/handle/11144/4755 DOI https://doi.org/10.26619/978-989$\underline{9002-14-2.7}$ 


\section{Resumo}

Neste capítulo pretende-se apresentar e problematizar a emergência e consolidação da esfera pública cultural que, a partir do séc. XVIII, configura um espaço comunicacional incontornavelmente marcado pelas práticas jornalísticas. "O espaço público moderno constituiu-se segundo o ideal liberal de uma síntese Razão - Publicidade - a «publicidade» com o sentido de publicitação, o acto eminentemente comunicacional do «tornar público», "dar a conhecer» (factos, opiniões e ideias) e fomentar o debate e livre circulação de ideias. Fórum de debate colectivo e de exercício da razão, o espaço público visa estabelecer e exprimir o interesse colectivo, a vontade geral, de uma forma autónoma relativamente ao Estado e em oposição ao Poder" (Esteves, 1998: 183).

O papel da crítica de arte na autonomização da esfera pública cultural foi crucial. À medida que cada vez mais pessoas entraram em contacto com as obras de arte, a função dos entendidos (cuja competência estava antes ligada a privilégios sociais) tornou-se dispensável, tendo sido assumida pela crítica profissional. O crítico ou 'árbitro das artes' assumiu-se como mandatário e pedagogo do público.

Foi em pleno século XVIII que os jornais se assumiram como instrumento da crítica de arte institucionalizada e os artigos dedicados à arte e à crítica cultural, objecto de discussão. 0 público esclarecia-se mediante a apropriação crítica das artes proporcionada por esses artigos.

A acompanhar a genealogia da esfera pública cultural, nomeadamente no contexto português, questiona-se neste capítulo o 
em primeiro o papel da imprensa, mais tarde da rádio e televisão e, recentemente, dos media digitais enquanto modalidades de tornar comum. 


\section{Abstract}

This chapter intends to present and discuss the emergence and consolidation of the cultural public sphere that, from the 18th century, configures a communicational sphere undeniably marked by journalistic practices. "The modern public space was constituted according to the liberal ideal of a Reason-Publicity synthesis - publicity with the sense of the act eminently communicational of "making public", "making known" (facts, opinions and ideas) and to encourage the debate and free circulation of ideas. As a forum for collective debate and the exercise of reason, the public space aims to establish and express the collective interest, the general will, in an autonomous way in relation to the State and in opposition to Power." (Esteves, 1998: 183)

The role of art criticism in the autonomy of the cultural public sphere was crucial. As more and more people came into contact with art works, the role of experts (whose competence was previously linked to social privileges) became unnecessary, having been assumed by professional critics. The critic or 'judge of the arts' came out as the public's mandate and pedagogue.

It was in the 18th century that newspapers became an instrument of institutionalized art criticism and articles devoted to art and cultural criticism, the subject of discussion. The public was enlighted by the critical appropriation of the arts provided by those articles.

Accompanying the genealogy of the cultural public sphere, namely in the European context, this chapter questions the role 
first of the press, later of radio and television and, more recently, of digital media as ways of making it common. 


\section{A emergência da esfera pública literária}

A esfera pública literária (a esfera pública cultural/artística que engloba a literatura, mas também domínios como a música, a pintura, a filosofia/discussão de ideias), estudada por Jürgen Habermas (1929-), emerge no século do lluminismo, o século em que Kant (1724-1804) enaltece a enunciação pública dos juízos que se referem à religião, às ciências e às artes (1784) e começa por ser uma esfera pública sem configuração política ${ }^{1}$. Esse ato em que pessoas privadas se reúnem em espaços de encontro e debate para publicamente partilharem raciocínios críticos deve-se, em primeiro lugar, ao processo de auto compreensão dessas pessoas em relação às experiências da sua própria privacidade.

"Na esfera da intimidade da família nuclear, os indivíduos privados vêem-se a si mesmos como independentes, até da esfera privada da sua actividade económica - como pessoas que podem entabular relações mútuas "puramente humanas»." (Habermas, 1962: 132)

Contrariamente ao que acontecia na Grécia Antiga, é na esfera privada que o indivíduo é livre e ao encontrar-se com o outro na esfera pública literária, atesta a sua subjetividade e a do outro, subjetividades que emergem das esferas de intimidade das suas famílias. "A subjetividade burguesa é essencialmente intersubjetividade, ou como Habermas a designa, orientada para o público." (Centeno, 2012: 69).

1 Como o próprio Habermas (1962) defende foi a Revolução Francesa a responsável pela politização da esfera pública que, da cultura e das artes, se consolida em uma esfera pública política. Mas foi também a Revolução Francesa que lançou a ligação prestigiante do Estado à cultura, passando a ser ele o responsável por democratizar o acesso de todos à cultura. 
As cidades, um pouco por toda a Europa, acolhem os espaços que constituem as primeiras experiências da esfera pública literária. Esta nova experiência da vida urbana substitui a centralidade de outrora da Corte. É nos cafés, nos salões e nos clubes que se discutem as novas obras antes de serem editadas e são esses os espaços em que a literatura se legitima.

"Tal como na Grécia antiga, também na emergente Europa moderna, a esfera pública se constituiu acima de tudo pelo medium da fala, na contraposição de argumentos, opiniões e pontos de vista diferentes através do intercâmbio dialógico de palavras faladas num espaço partilhado." (Thompson, 1996: 10)

Nesses salões e cafés, promove-se a discussão entre pessoas privadas.

“Uma série de critérios institucionais parecem atravessá-los: é exigida uma espécie de sociabilidade que pressupõe a igualdade de status e em que a autoridade do argumento fala mais alto do que qualquer hierarquia social; em segundo lugar, torna-se possível problematizar uma série de áreas que até então não eram consideradas questionáveis (à medida que as obras filosóficas e literárias, as obras de arte em geral, são produzidas para e circulam no mercado, esses bens culturais transformam-se em mercadorias e tornam-se, por princípio, acessíveis a todos; as pessoas privadas têm oportunidade de conversar sobre algo que até então permanecia sagrado em virtude da não-discursivização promover a sua própria autoridade); em terceiro lugar, esse mesmo processo que transforma a arte em mercadoria e 
consequentemente em algo questionável leva à abertura do leque de públicos (constituídos por pessoas privadas que, enquanto leitores, ouvintes e espectadores, se apropriam dos objetos em discussão)." (Centeno, 2012: 69-70)

A abertura temática generaliza-se não só no sentido da sua relevância, mas também da sua acessibilidade: todos devem poder participar e a discussão torna-se um meio de apropriação. Os critérios institucionais da esfera pública literária sustentam a qualidade do discurso e a quantidade de participação.

\footnotetext{
"Onde quer que o público se estabelece de forma institucional como um grupo estável de interlocutores, não se equipara ao público, mas reivindica agir em seu nome, como seu porta-voz, e mesmo, talvez, como seu educador - a nova forma da representação burguesa." (Habermas, 1962: 116-7)
}

Discutir é partilhar juízos e quem o faz não tem de deter nenhuma competência em especial, na medida em que no público qualquer um pode reivindicar competência.

\section{Imprensa consagrada à arte e à crítica cultural}

O papel da crítica de arte na autonomização da esfera pública literária é central. À medida que um número cada vez maior de pessoas entra em contacto com as obras de arte, os entendidos, que antes ligavam a competência do especialista a privilégios sociais (a pintura, por exemplo, era direcionada aos colecionadores especializados da nobreza), começam a ser dispensados e são substituídos pela crítica profissional. 
As discussões tidas nos cafés e nos salões prolongam-se nos textos publicados nos jornais e a crítica consagrada à arte e à cultura assume-se como organizadora do juízo do público. $O$ crítico ou 'juiz das artes' assume-se como mandatário do público e como seu pedagogo já que é através da apropriação crítica das artes que o público se esclarece. Enquanto porta-vozes do público, "não reconhecem nenhuma autoridade para além da do melhor argumento e se sentem unidos com todos os que se dispõem a deixar-se convencer por argumentos" (Habermas, 1962: 122).

"Se, num primeiro momento, as discussões tidas nos cafés e
nos salões derivavam da apresentação pública das próprias
obras, com a emergência da imprensa consagrada à arte e à
crítica cultural são os artigos de jornal que se tornam objeto de
discussão." (Centeno, 2012: 71)

As pessoas privadas, que enformaram a esfera pública de uma argumentação literária que se emancipou dos cafés e dos salões, passam a manter-se reunidas através da instância mediatizadora da imprensa e da crítica profissional.

O conjunto dos destinatários, consumidores e críticos das obras de arte, que se reúne e atua nesses novos espaços de sociabilidade constitui a realidade social que enforma o conceito de 'público', tal como o entendemos desde a modernidade. Associados a essas primeiras experiências do público surgem novos domínios de vida que são objeto de discussão e que mobilizam a 
opinião pública (a opinião devidamente fundamentada que promove a força do melhor argumento).

A facilidade na mediatização desta realidade social, que continua pelo século XIX, decorre de a sua constituição não exigir a proximidade física das pessoas e dispensar a presença direta de uns perante os outros, apesar de a experiência do público só se poder constituir após a experiência prévia de uma certa forma de influência recíproca imediata, estabelecida em contactos sociais intensos ${ }^{2}$.

A cultura, mais especificamente a literatura, foi então o domínio que deu forma aos critérios modernos do Público e do Privado.

"Enfatizar a natureza pública da esfera cultural é extremamente importante na medida em que os teóricos da ciência política tendem a marginalizar as questões culturais (especialmente as estéticas) considerando-as privadas, pessoais e 'nem verdadeiras nem falsas', e por isso irrelevantes no processo de tomada de decisão." (Hohendahl, 1992: 108)

\section{A transformação estrutural da esfera pública cultural}

A interpenetração entre a esfera do poder público e o domínio privado ocorrida a partir do séc. XIX conduz, em traços gerais, ao figurino atual do espaço público e da opinião pública

2 "Os públicos criam uma forma original de divisão das sociedades: a divisão simbólica, fundada em motivos e convicções. Este carácter simbólico dos públicos confere-lhes grande homogeneidade e uma forma duradoura: as suas motivações não são materiais e a sua mobilização não tem por base a paixão ou meramente a ação. $O$ que une e mantém reunidos os membros de um público é a comunhão de ideias partilhadas e, acima de tudo, a consciência dessa comunhão." (Centeno, 2012: 72) 
- refuncionalizados, 'refeudalizados'. A estatização da Sociedade e a socialização do Estado transformaram estruturalmente a esfera pública cultural.

Situando-nos em meados do século XX, o público deixou de se envolver em discussões para pensar a cultura, que estavam intimamente ligadas à leitura das obras que se fazia na esfera privada para se tornar um consumidor de cultura, que ocupa o seu tempo de lazer num meio social em que não precisa de encontrar nenhuma continuidade em discussões.

"Actualmente, a atrofia da imaginação e da espontaneidade do
consumidor cultural não precisa de ser reduzida a mecanismos
psicológicos. Os próprios produtos - e entre eles em primei-
ro lugar o mais característico, o filme sonoro - paralisam essas
capacidades em virtude da sua própria constituição objectiva."
(Adorno \& Horkheimer, 1944: 119)

Com o consumo coletivo perde-se a comunicação pública sobre o assimilado.

"O consumismo cultural desenvolve-se à margem dos públicos tradicionais (os círculos de cultura que dinamizavam tanto a produção como a receção das obras de arte), passando antes a objectivar uma massa, definida exclusivamente pela sua capacidade aquisitiva de bens; com esta viragem, a dinâmica cultural adquire uma nova razão de ser fundamental: o valor mercantil." (Centeno, 2012: 78) 
Da produção ao consumo, o ciclo cultural desenvolve-se segundo os padrões consumistas e passa a estar subordinado à lógica do lucro.

\begin{abstract}
"A dependência em que se encontra a mais poderosa sociedade radiofónica em face da indústria eléctrica, ou a do cinema relativamente aos bancos, caracteriza a esfera inteira, cujos sectores individuais por sua vez se interpenetram numa confusa trama económica." (Adorno \& Horkheimer, 1944: 115)
\end{abstract}

A designação de cultura de massa resulta da sujeição às necessidades de distração e diversão de grupos de consumidores com níveis de formação relativamente baixos, em vez de, inversamente formar o público. A grande massa é perspetivada, seguindo os teóricos da Escola de Frankfurt ou, também designada, Teoria Crítica, pela negativa, ela é constituída por incultos não instruídos e não cultivados. Para Theodor Adorno (1903-1969), um dos teóricos de referência dessa escola e de quem Jürgen Habermas foi aluno,

\footnotetext{
"as massas não são o factor primeiro, mas um elemento secundário, um elemento de cálculo; acessório da maquinaria. O consumidor não é rei, como a indústria cultural gostaria de fazer crer, ele não é o sujeito dessa indústria, mas o seu objecto." (Adorno, 1987: 288)
}

já que a mercantilização da cultura resulta dos meios de comunicação de massa, da tecnologia e sua consequente capacidade de reprodução e seriação. Estaríamos a assistir "à dissolução das 
clivagens classistas, regionais, sexuais, étnicas, etc., pela força de um consumo nivelador, baseado no mínimo denominador comum de gostos e atitudes" (Lopes, 2000: 52).

O mercado desempenha um papel central em todo este processo: à medida que permite ao público o acesso a bens culturais cada vez mais baratos, facilita economicamente o acesso a um público cada vez maior, fazendo com que a cultura se afaste dos momentos em que a receção exige uma certa escolarização. "Lidar com cultura exercita o espírito, ao passo que o consumo de cultura de massa não deixa qualquer rasto; transmite uma espécie de experiência que não é cumulativa, mas regressiva." (Habermas, 1962: 290). Transitou-se do discurso cultural para o consumismo cultural, de uma cultura claramente separada do mercado para um produto de entretenimento consumido nos tempos livres ${ }^{3}$.

“Este processo delimita claramente um núcleo preciso de in-
teresses sociais (e de interessados): os interesses económicos
que podem estender a sua actividade social (e as possibilidades
de obtenção de benefícios) a um domínio até então quase incó-
lume à lógica mercantil.” (Centeno, 2012: 79).

O consumo público sai sacrificado, na medida em que a mercantilização dos bens culturais interrompe as experiências da troca subjetiva e da comunhão de sentimentos.

3 A mercantilização da produção cultural começa com a edição de livros, seguida do teatro que passa para salas de espetáculos, a música que passa a ser ensinada e admirada em auditórios; as pinturas expostas em museus e o mercado das cópias de quadros (Santos Silva, 2011a). 
“O princípio impõe que todas as necessidades sejam apresentadas (ao consumidor) como podendo ser satisfeitas pela indústria cultural, mas, por outro lado, que essas necessidades sejam de antemão organizadas de tal sorte que ele se veja nelas unicamente como um eterno consumidor, como objecto da indústria cultural." (Adorno \& Horkheimer, 1944: 133)

Os teóricos da Escola de Frankfurt também têm uma ideia clara em relação ao papel dos meios de comunicação de massa no consumismo cultural, já que captam o público enquanto ouvinte ou espectador, tirando-Ihe a distância da 'emancipação', ou seja, a oportunidade de se envolverem em discussões. O raciocínio de um público-leitor dá tendencialmente lugar à troca de opiniões e preferências dentro da família, do grupo das pessoas com a mesma idade, dos colegas de trabalho e da vizinhança.

Os meios de comunicação de massa só aparentemente recriam uma esfera pública que cede o seu lugar à indústria cultural, "a imprensa enquanto meio potencial de promoção do diálogo público é destronada pelos mass media, profundamente imiscuídos numa estrutura de dominação que se expande da esfera da produção para todos os aspetos da vida social" (Centeno, 2012: 81). Os mass media tornam-se produtores da 'consciência de uma única dimensão', tal como destaca Herbert Marcuse (18981979), na medida em que aceita e reflete a ordem social existente, rejeitando qualquer tentativa de falar de valores ou de possibilidades além dela. 
O aparecimento dos media comerciais contribuiu para uma rutura entre a imprensa e um público ativo. "Se antes se convidava o leitor a participar no debate e na ação, agora oferece-se um 'state of the art' do próprio mundo dirigido a um público que não se reconhece, na medida em que está excluído, ausente." (Centeno, 2012: 81).

A 'cultura' que os meios de comunicação de massa difundem é uma cultura de integração: integra informação e raciocínio, formas publicitárias com formas literárias.

"A esfera pública assume funções de propaganda: quanto mais ela pode ser utilizada como meio de influir política e economicamente, mais apolítica ela se torna e mais aparenta estar privatizada. (...) A esfera pública crítica é absorvida pela esfera pública do consumismo cultural." (Centeno, 2012: 82)

A este processo não é alheio o aparecimento de formas tecnologicamente mediatizadas de comunicação pública. Com elas, a visibilidade dos domínios do público e do privado modifica-se, deixando de estar associada à partilha de um mesmo espaço físico.

"Hoje os jornais e as revistas, a rádio e a televisão são os media da esfera pública" (Habermas, 1964: 49), são o principal instrumento de transmissão do discurso e o próprio espaço de exercício e de formação da opinião pública, assumindo-se nessa medida como verdadeira instância de socialização em matérias relativas à formação cívica e política dos cidadãos. 
No entanto, o conteúdo concreto do espaço público é condicionado pela forma como as mensagens dos mass media são reapropriadas pelos agentes sociais no contexto da sua vida quotidiana. As mensagens mediáticas raramente valem por si só: elas são objeto de reelaborações discursivas ao nível da receção que as reconduzem ao discurso público - o discurso que fluí na comunicação quotidiana. Estamos perante uma comunidade de públicos, em que os órgãos de comunicação de massa ampliam e animam o meio de comunicação fundamental, a discussão.

O que quer dizer que paralelamente a este processo existem pessoas, ainda que isoladas, que ainda procuram formar literariamente a sua opinião, no entanto, apesar de disporem de uma opinião capaz de se tornar pública, ela é de facto não-pública na medida em que circula num meio relativamente restrito. É a esfera da comunicação de uma opinião não-pública,

\begin{abstract}
"A relação de comunicação de um público de pessoas privadas que faz uso da sua razão desfez-se; a opinião pública que em tempos dela resultava decompôs-se em parte em opiniões informais de pessoas privadas sem um público e em parte concentrou-se nas opiniões formais das instituições publicisticamente activas." (Habermas, 1962: 404)
\end{abstract}

Uma opinião rigorosamente pública só pode estabelecer-se à medida que os dois sectores da comunicação, o formal e o informal, passem a ser mediados por um outro que é o da 'publicidade crítica'. Tal mediação só é possível através da participação de pessoas privadas num processo de comunicação formal conduzido através das esferas públicas internas às organizações. 


\section{O discurso e as suas propriedades curativas}

A par das formas espetaculares que as tecnologias proporcionam, circulam também as formas discursivas convencionais, disponíveis em articulações racionais que podem dar lugar a processos de esclarecimento. Apesar da crise da comunicação pública que caracteriza as sociedades contemporâneas, Habermas continua a promover a força do melhor argumento e a reafirmar as propriedades curativas do discurso, o que lhe permite afirmar que o espaço público das sociedades pós-liberais não se esvaziou por completo das suas tradicionais funções críticas e emancipadoras. O potencial inacabado do projeto iluminista tem condições de se atualizar.

A questão fulcral que permite operar uma viragem teórica nesta matéria passa por considerar a linguagem e a comunicação como medium por excelência de afirmação da condição humana. As formas generalizadas de comunicação (das quais fazem parte os meios de comunicação de massa) não suprimiram a compreensão pela linguagem.

O entendimento dos fenómenos da cultura e da comunicação passa pelos processos de massificação (de uma comunicação altamente formalizada, abstrata e mediatizada), não perdendo de vista os mecanismos convencionais da atividade simbólica e afastando a ideia de pura manipulação. É necessário ter também presente que o conceito de massa é a banalização de uma realidade social complexa, em que confluem diversas formações 
sociais e o de cultura de massa apenas dá conta de uma única dimensão da cultura e da comunicação atuais.

As tensões que se fizeram e fazem sentir no interior do campo dos media geram contra movimentos culturais questionantes e críticos dos fenómenos da massificação e os próprios efeitos 'destrutivos' desses mesmos fenómenos nunca chegaram a ser totais e irremediáveis, nem é credível que alguma vez cheguem a ser.

"O contributo de Habermas vai no sentido de redescobrir as propriedades curativas do diálogo, na medida em que todas as formas de comunicação humana, mesmo sob a disseminação das massas, são essencialmente relações entre indivíduos que derivam da estrutura elementar que é o diálogo, a partilha de expectativas de comportamento intersubjetivamente válidas." (Centeno, 2012: 90) ${ }^{4}$

As práticas esclarecidas constroem-se no seio da competência comunicativa que os participantes usam mesmo sob condições díspares de comunicação.

\footnotetext{
4 Esta conceção dialógica da esfera pública tem sido alvo de crítica. Segundo John B. Thompson, esta conceção não ilustra a comunicação estabelecida através dos meios de comunicação de massa e consequentemente o tipo de esfera pública que desencadearam, já que a situação que geraram, onde a receção dos produtos se converteu numa forma de apropriação privada, tem pouco a ver com o intercâmbio dialógico que caracterizou os indivíduos que se reuniam nos cafés e nos salões no início da Europa moderna. Sendo assim considera que os meios de comunicação em massa criaram um novo tipo de publicidade ('publicness') que se desvinculou da conceção da participação que tem de acontecer num espaço comum. "Ela se des-espacializou e tornou não-dialógica, à medida que se vinculou crescentemente à classe específica de visibilidade produzida e factível pelos meios de comunicação (especialmente a televisão)." (Thompson, 1996: 11)
} 
A própria esfera do consumo tem de ser vista como uma esfera complexa de experiências vividas, de competências e situações em que coabitam elementos contraditórios 5 . Elas são práticas críticas no seio da vida quotidiana, ligadas muitas vezes a elementos da cultura popular, em que os indivíduos analisam criticamente a situação e adaptam a receção às suas próprias necessidades ${ }^{6}$.

A conceção pragmática da comunicação, em que o diálogo proporciona a partilha de expetativas de comportamento intersubjetivamente válidas, repõe a questão do consumo ao revelar que atendemos, não só ao conteúdo das mensagens veiculadas pelos mass media (imprensa, cinema, rádio, fotografia e televisão), mas também às relações que se estabelecem entre o comunicador e a sua audiência, ou seja, a mensagem dá conta da natureza da relação social estabelecida. Um ato de fala ao afirmar qualquer coisa sobre o mundo simultaneamente invoca uma relação entre falante e ouvinte. "As notícias dizem-nos não só o que aconteceu no mundo hoje mas quem somos na relação com esse mundo." (Hallin, 1985: 123).

\footnotetext{
5 A conceção de Habermas na fase posterior da sua obra relativamente à receção dos produtos dos meios de comunicação de massa distancia-se da conceção defendida pelos pensadores da primeira Teoria Crítica, que a entendiam como um ato manipulado e irreflexivo de consumo, acentuando a passividade dos indivíduos. Em vez disso, Habermas acentua o facto de os indivíduos se situarem em contextos socio-históricos definidos, o que faz com que recebam as mensagens em distintos graus de atenção, as interpretem ativamente, lhes atribuam sentido e as relacionem com outros aspetos das suas vidas. A apropriação das mensagens é um processo em que os indivíduos constroem ativamente o sentido e adaptam as mensagens ao seu contexto socio-histórico, transformando-as no decorrer do processo de assimilação.

6 Pense-se nas manifestações nacionais pela cultura em inícios de junho de 2020, sob o lema "Parados. Nunca Calados"; são atividades concretas que atraem a atenção de outros grupos cujos membros são potenciais participantes de uma prática 'iluminada', neste caso para obrigar o Estado português a intervir na área da cultura, fortemente afetada pela pandemia por SARS CoV-2.
} 
As relações sociais estabelecidas dependem das relações sociais que caracterizam as profissões implicadas, pense-se nos jornalistas ou em todos os profissionais ligados à produção cultural, como sejam, diretores artísticos, gestores culturais, programadores, etc. Peter Grahame salienta que a aplicação da pragmática à clarificação de casos particulares requer uma estratégia complementar, que mostre como é que a situação do participante é compreensível não só em termos de qualificações gerais para o discurso, mas também em termos de membro de práticas culturais particulares. "Proponho designar esta estratégia complementar 'pragmática cultural'. Nela a reflexão sobre a pertença cultural é a condição para analisar as determinações particulares da validade." (Grahame, 1985: 152). Complementa a pragmática formal, na medida em que clarifica o horizonte particular dentro do qual as pretensões de validade do que é afirmado se articulam.

\section{O papel da crítica}

Da esfera da crítica passou a fazer parte um conjunto de especialistas (de entre os profissionais dos meios de comunicação é importante distinguir os que só desenvolvem o vetor informativo, os jornalistas, e os que desenvolvem os dois vetores, os críticos $^{7}$ ) que tem como função informar e contribuir para

\footnotetext{
7 "Os jornalistas desenvolvem uma primeira intermediação com os públicos, dando a conhecer, através dos canais vários da Comunicação Social, a existência de um espectáculo, a sua data, o seu local e toda uma série de informação complementar sobre os artistas e conteúdos do espectáculo. Desde logo, a existência do espectáculo, na medida em que lhe garante uma visibilidade pública, tão mais destacada quanto a importância do espectáculo. (...) Os críticos situam-se numa escala de comentadores especializados que, para além de um papel informativo, fornecem uma primeira apreciação dos espectáculos, interpretando-os e avaliando-os." (Madeira, 2002: 127)
} 
a apreciação pública dos eventos, o seu papel situa-se ao nível da divulgação e valoração da obra, geralmente pós-criação e produção. Desenvolvem, portanto, um importante papel de mediação entre a esfera da criação e os públicos/espectadores, sendo concorrentes e cúmplices dos programadores no ato de 'nomear' os valores artísticos (Madeira, 2002: 127). A crítica aos eventos é também uma crítica à seleção programática e aos 'autores da programação'.

Quer os críticos, quer os programadores detêm saberes específicos (teóricos e práticos) e familiaridade com a esfera pública cultural, o que lhes confere o direito de discernir o legítimo do ilegítimo, bem como produzir 'discursos autorais'. Detém o 'poder simbólico',

"poder de constituir o dado pela enunciação, de fazer ver e fazer crer, de confirmar ou de transformar a visão do mundo e, deste modo, a acção sobre o mundo, portanto o mundo; poder quase mágico que permite obter o equivalente daquilo que é obtido pela força (física ou económica), graças ao efeito específico de mobilização, só se exerce se for reconhecido, quer dizer, ignorado como arbitrário. Isto significa que o poder simbólico (...) se define numa relação determinada - e por meio desta entre os que exercem o poder e os que lhe estão sujeitos, quer dizer, isto é, na própria estrutura do campo em que se produz e se reproduz a crença." (Bourdieu, 1989: 14-5).

O crítico desenvolve uma 'informação contextualizada e enquadrada' (categoriza e classifica a obra), uma 'reflexão judicativa' 
(valoração estética da obra nas suas qualidades e defeitos intrínsecos) e uma 'reflexão interpretativa' (preocupação em tornar o evento inteligível e passível de apreensão por parte dos públicos). Este tríptico confere ao crítico a capacidade de gerar a celebração da obra de arte e dos seus intervenientes (Madeira, 2002: 129).

\footnotetext{
“Não se consegue imaginar como é que o público pode ser constituído, como se pode expressar, participar, ter um efeito, sem a mediatização das várias formas de comunicação de massas. Tornar algo público significa apresentá-lo nos media; manter algo fora dos media corresponde a uma aniquilação simbólica." (Livingstone, 2005: 26)
}

Quando os públicos entram em contacto com as manifestações artísticas e os diferentes pontos de vista oferecidos pelos meios de comunicação de massa e mais recentemente pelos media digitais, são audiência antes de ser espectadores, o que configura a importância da atividade destes meios. Com esta indicação, não queremos opor o conceito de audiência ao de público, até porque as relações comunicacionais atuais,

\footnotetext{
"são caracterizadas quer pela mediação dos públicos, quer pela participação em audiências. (...) Num mundo mediatizado, as audiências e os públicos, bem como as comunidades, as nações, os mercados e as multidões são compostas pelas mesmas pessoas" (Livingstone, 2005: 17).
} 
Também não queremos opor a função desses meios de divulgação de eventos e manifestações artísticas com a de crítica e reflexão, "por um lado, o jornalismo cultural insere-se na lógica de mercado e do entretenimento; por outro, permanece como espaço de produção intelectual, com uma forte presença autoral, opinativa e analítica que extravasa as fronteiras da mera cobertura noticiosa" (Santos Silva \& Silva, 2017: 91). Contrariando os resultados de alguns estudos (Baptista, 2017; Santos Silva, 2012), que mostram como a crítica tem vindo a perder terreno quando comparada com outros géneros como a review ou o roteiro, é fundamental o recentramento da atividade do jornalista cultural na enunciação pública de juízos de valor para assim enformar o tornar comum. Concordamos e destacamos J. S. Faro (2007) quando afirma que a atividade jornalística dedicada à cultura,

\begin{abstract}
“não pode ser vista apenas como uma operação que reitera os valores e os signos da cultura de massa, meramente voltada para o entretenimento, mas deve ser vista também como um espaço público de reflexão e análise de questões que a produção intelectual (artística ou académica) suscita no conjunto da sociedade" (apud Santos Silva, 2011: 110).
\end{abstract}

As modalidades de tornar comum exercidas pelos diferentes meios de comunicação devem, assim, continuar as funções de mandatários e pedagogos de um público que delas precisa para se esclarecer. 


\section{Bibliografia}

Adorno, T. \& Horkheimer, M. (1985). Dialéctica do Esclarecimento: Fragmentos Filosóficos (or. Dialektik der Aufklärung - Philosophische Fragmente), Rio de Janeiro, Zahar.

Adorno, T. (1987). "A Indústria Cultural” in Cohn, G. (org.), Comunicação e Indústria Cultural. São Paulo: T. A. Queiroz Editor, pp. 285-295.

Baptista, C. (org.) (2017). A Cultura na Primeira Página - Uma década de jornalismo cultural na imprensa em Portugal. Lisboa: Escritório Editores.

Bourdieu, P. (1989). O Poder Simbólico. Lisboa: Difel.

Centeno, M. J. (2012). As Organizações Culturais e o Espaço Público, A Experiência da Rede Nacional de Teatros e Cineteatros. Lisboa: Colibri/ IPL.

Esteves, J. P. (2003). A Ética da Comunicação e os Media Modernos, Legitimidade e Poder nas Sociedades Complexas, 2 a ed. Lisboa: Fundação Calouste Gulbenkian.

Grahame, P. (1988). "Criticalness, Pragmatics, and Everyday Life: Consumer Literacy as Critical Practice" in Forester, J. (ed.), Critical Theory and Public Life. Cambridge: The Mit Press, pp. 147-174.

Habermas, J. (1964). "The Public Sphere: An Encyclopedia Article", New German Critique, 3 (Fall), pp. 49-55.

(2012). A Transformação Estrutural da Esfera Pública (or. Strukturwandel der Öffentlichkeit), Lisboa: FCG.

Hallin, D. (1988) - "The American News Media: A Critical Theory Perspective" in Forester, J. (ed.), Critical Theory and Public Life, Cambridge: The Mit Press, pp. 121-146.

Hohendahl, P. (1992). "The Public Sphere: Models and Boundaries" in Calhoun, C. (ed.) - Habermas and the Public Sphere. Cambridge: The MIT Press, pp. 99-108. 
Kant, I. (1996). "An Answer to the Question: 'What is Enlightenment?'” in Cahoone, L. (ed.), From Modernism to Postmodernism: An Anthology. Oxford: Blackwell Publishers, pp. 51-57.

Livingstone, S. (ed.) (2005). Audiences and Publics: When Cultural Engagement Matters for the Public Sphere, Changing Media, Changing Europe, Vol. 2. Bristol: Intellect Books.

Lopes, J. T. (2000). A Cidade e a Cultura. Porto: Afrontamento.

Madeira, C. (2002). Novos Notáveis, os Programadores Culturais. Oeiras: Celta.

Santos Silva, D. \& Silva. M. T. (2017). "Definições, tendências e marcas discursivas do jornalismo cultural" in Baptista, C. (org.), A Cultura na Primeira Página - Uma década de jornalismo cultural na imprensa em Portugal. Lisboa: Escritório Editores, pp. 87-108.

Santos Silva, D. (2012). Cultura e Jornalismo Cultural - Tendências e Desafios no Contexto das Indústrias Culturais e Criativas. Lisboa: Media XXI.

Santos Silva, D. (2011). "Possibilidades políticas do jornalismo cultural digital na perspectiva da democracia deliberativa", Estudos em Comunicação, no9, pp. 103-117.

Thompson, J. B. (1996) - "La Teoria de la Esfera Pública", Voces y Culturas, no 10, Barcelona, pp. 1-12. 